\title{
Principles and Applications of Dual-Polarization Weather Radar. Part I: Description of the Polarimetric Radar Variables
}

\author{
MATTHEW R. KUMJIAN \\ Advanced Study Program, National Center for Atmospheric Research*, Boulder, Colorado
}

(Manuscript received 22 April 2013; review completed 7 August 2013)

\begin{abstract}
The United States Weather Surveillance Radar-1988 Doppler (WSR-88D) radar network has been upgraded to dual-polarization capabilities, providing operational and research meteorologists with a wealth of new information regarding the types and distributions of hydrometeors within precipitating storms, as well as a means for improved radar data quality. In addition to the conventional moments of reflectivity factor at horizontal polarization $\left(Z_{H}\right)$, Doppler velocity $\left(V_{r}\right)$, and Doppler spectrum width $(W)$, the new variables available from upgraded radars are the differential reflectivity $\left(Z_{\mathrm{DR}}\right)$, differential propagation phase shift $\left(\Phi_{\mathrm{DP}}\right)$, specific differential phase $\left(K_{\mathrm{DP}}\right)$, and the co-polar correlation coefficient $\left(\rho_{\mathrm{hv}}\right.$ or $\left.C C\right)$. In the first part of this review series, a description of the polarimetric radar variables available from the newly polarimetric WSR-88D radars is provided. An emphasis is made on their physical meaning and interpretation in the context of operational meteorology.
\end{abstract}

\section{Introduction}

Polarization diversity radar for use in remote sensing of precipitation has a rich history, dating back to its first use in the 1950s by scientists in the United Kingdom (Browne and Robinson 1952; Hunter 1954), United States (Newell et al. 1955; Wexler 1955), and the Soviet Union (e.g., Shupyatsky 1959; Gerzenshon and Shupyatsky 1961; Shupyatsky and Morgunov 1963; Minervin and Shupyatsky 1963; Morgunov and Shupyatsky 1964). Beginning with this pioneering work in the United Kingdom, United States, and the Soviet Union, the history of developments in the field can be found in more detail in Seliga et al. (1990). Considerable contributions by Canadian scientists with circular polarization radar (e.g., McCormick and Hendry 1970, 1975; Hendry and McCormick 1974) furthered remote sensing precipitation studies. The "modern era" of research with orthogonal linear polarization (i.e., dual-polarization) radar began in the United States with the papers by Seliga and Bringi (1976, 1978). Significant contributions by Jameson (1983a,b, 1985a,b), Sachidananda and Zrnić (1985, 1986, 1987), Jameson and Mueller (1985), and
Balakrishnan and Zrnić (1990a,b) improved the understanding and interpretation of the variables available with linearly orthogonal polarimetric radars, which are described herein.

The United States Weather Surveillance Radar1988 Doppler (WSR-88D) radar network upgrade to dual-polarization capabilities is now complete. Now, all National Weather Service meteorologists have at their disposal a wealth of new information gained from these polarimetric radar observations. Additionally, similar upgrades are occurring worldwide. Thus, radar polarimetry is an emerging tool that can be applied to numerous operational situations and used to improve warnings, short-term forecasts, and quantitative precipitation estimation. The purpose of this review series is to provide an overview of radar polarimetry, and the various applications of polarimetric weather radar that may be of use to operational meteorologists and hydrologists.

The organization of this series is as follows. In this first part, descriptions of the polarimetric radar variables are provided, with an emphasis on their

*The National Center for Atmospheric Research is sponsored by the National Science Foundation.

Corresponding author address: Dr. Matthew R. Kumjian, NCAR, P.O. Box 3000, Boulder, CO 80307

E-mail: kumjian@psu.edu 
physical interpretation. The intended audience is operational meteorologists and others that make use of weather radar data. In the subsections below, each variable is introduced, general characteristics are provided, and this is followed by specific discussion of implications for different types of precipitation particles. Various applications of dual-polarization radar observations will be discussed in Part II (Kumjian 2013a), with examples of data for each. In Part III (Kumjian 2013b), common artifacts of polarimetric radar measurements will be discussed, along with a description of how to identify such artifacts and distinguish them from real, physical features of precipitating systems.

\section{Description of the polarimetric radar variables}

Conventional (single-polarization) WSR-88D radars operate by transmitting pulses of electromagnetic (EM) radiation and "listening" for echoes returned from various atmospheric targets, including precipitation, biological, and inorganic (e.g., dust, chaff, and smoke) scatterers. The energy propagates through the atmosphere as an EM wave with the electric field vector oscillating in the horizontal plane parallel to the ground; therefore, these waves are said to be horizontally polarized. When a horizontally polarized wave illuminates a particle in the atmosphere, the particle behaves as a tiny antenna, emitting radiation in all directions, with the amplitude of this "scattered" energy related to the size, shape, and orientation of the target, as well as its physical composition (e.g., liquid or ice). The particle's physical composition affects scattering through the complex refractive index or complex relative permittivity, which can be thought of as how "reflective" a particle is to EM radiation.

Consider a spherical hydrometeor that is small compared to the radar wavelength. When the particle is illuminated by a horizontally polarized radar wave, the particle behaves like a horizontal dipole antenna that becomes excited and scatters energy having horizontal polarization, whereas it behaves like a vertical dipole antenna and scatters energy with vertical polarization when excited by a vertically polarized radar wave. Dual-polarization WSR-88D radars exploit this fact by transmitting radiation with

\footnotetext{
1 The complex refractive index $n$ is related to the complex relative permittivity, $\varepsilon$, as $n \approx \varepsilon^{1 / 2}$.
}

horizontal polarization and vertical polarization simulltaneously (Fig. 1). By comparing the signals received from returns at each polarization, one can glean information about the size, shape, and orientation of targets within the radar sampling volume.

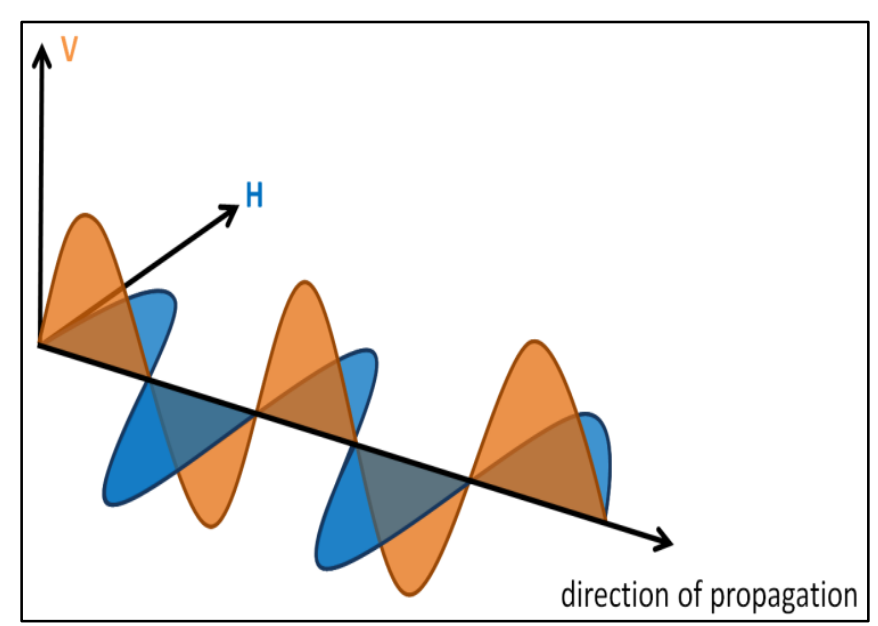

Figure 1. Schematic illustrating the simultaneous propagation of horizontally polarized (blue) and vertically polarized (orange) electromagnetic waves. The plane made by the axes labeled $\mathrm{H}$ and $\mathrm{V}$ is called the "plane of polarization" and is normal to the direction of wave propagation. Click image for an external version; this applies to all figures hereafter.

Prior to the upgrade to dual polarization, singlepolarization WSR-88D radars (hereafter referred to as "conventional") measured three moments: radar reflectivity factor $(Z)$, which is proportional to the power of the received signal, Doppler velocity $\left(V_{r}\right)$, which is determined from the power-weighted mean Doppler frequency shift of targets within the radar sampling volume and involves measurements of the received signal phase, and Doppler spectrum width $(W)$, which is a measure of the variability of Doppler velocities within the sampling volume [see Doviak and Zrnić (1993) or Rinehart (2004) for more detailed explanations]. Because the conventional radars send and receive signals at horizontal polarization, all three of these moments are measured at horizontal polarization, which will be denoted hereafter by a subscript $\mathrm{H}\left(Z_{H}\right.$, $\left.V_{H}, W_{H}\right)$. Dual-polarization radars can measure these three moments at both horizontal and vertical (V) polarizations: $Z_{H}, Z_{V}, V_{H}, V_{V}, W_{H}$, and $W_{V}$. Note that because the conventional (pre-upgraded) WSR-88D radars transmit and receive signals at only one polarization, they are called single-polarization radars. In contrast, the upgraded WSR-88Ds (that transmit and receive radiation at two polarizations) are called dual- 
polarization or polarimetric ${ }^{2}$ radars. Dual-polarization WSR-88D radars provide the single-polarization moments $Z_{H}, V_{H}$, and $W_{H}$ of essentially the same quality as before ${ }^{3}$.

Meaningful information is obtained by comparing the amplitudes and phases of the signals returned at $\mathrm{H}$ and $\mathrm{V}$ polarizations, providing a suite of new variables. The difference in logarithmic reflectivity factors at $\mathrm{H}$ and $\mathrm{V}$ polarizations (i.e., $Z_{H}-Z_{V}$, where $Z_{H}$ and $Z_{V}$ are expressed in dBZ) is called the differential reflectivity, or $Z_{\mathrm{DR}}$. Taking the difference in phase shift between the two polarizations provides the differential phase shift, or $\Phi_{\mathrm{DP}}$. Taking the correlation between returned signals at $\mathrm{H}$ and $\mathrm{V}$ polarization provides the co-polar correlation coefficient, denoted as $\rho_{\mathrm{hv}}$ in the scientific literature and $C C$ in the operational community. Each of these variables is introduced below and discussed in the context of a physical interpretation in different types of atmospheric scatterers useful for meteorological applications. Note that values for the polarimetric variables given apply to S-band radars only unless otherwise stated. Other reviews of the polarimetric radar variables can be found in the papers by Herzegh and Jameson (1992), Hubbert et al. (1998), Zrnić and Ryzhkov (1999), Straka et al. (2000), and Ryzhkov et al. (2005a). More technical expositions are presented in the textbooks by Doviak and Zrnić (1993) and Bringi and Chandrasekar (2001).

\section{a) Differential reflectivity, $Z_{D R}$}

The differential reflectivity $\left(Z_{\mathrm{DR}}\right)$ was first introduced by Seliga and Bringi (1976) for precipitation measurements. It is the logarithmic ratio of the reflectivity factors at $\mathrm{H}$ and $\mathrm{V}$ polarizations, and therefore is a measure of the reflectivity-weighted axis ratio (or shape) of the targets. Thus, for spherical targets that return equal power at $\mathrm{H}$ and $\mathrm{V}$ polarizations, $Z_{\mathrm{DR}}$ is 0 $\mathrm{dB}$. For scatterers that are small compared to the radar wavelength (i.e., "Rayleigh" scatterers, which are most hydrometeors except for large hail at the S-band

\footnotetext{
2 The term "dual-polarimetric" is redundant, as the word "polarimetric" implies the use of polarization diversity for measurements; thus, "dual-polarimetric" should be avoided.

${ }^{3}$ Splitting the transmitted power between $\mathrm{H}$ and $\mathrm{V}$ channels results in a $3-\mathrm{dB}$ loss in the signal-to-noise ratio compared to conventional WSR-88D radars. However, improved signal processing techniques (e.g., Ivić et al. 2009) have mitigated adverse effects of this 3-dB loss on signal detection and algorithm performance.
}

operating frequency of WSR-88D radars), those with their major axis aligned in the horizontal plane produce positive $Z_{\mathrm{DR}}$ and those with their major axis aligned in the vertical direction produce negative $Z_{\mathrm{DR}}$. $Z_{\mathrm{DR}}$ also is affected by the physical composition and/or density of particles. For a particle of a given size and shape, $Z_{\mathrm{DR}}$ is enhanced as the complex refractive index increases. The complex refractive index of water is much greater than that of ice. Thus, the $Z_{\mathrm{DR}}$ of an oblate water drop is larger than the $Z_{\mathrm{DR}}$ of an ice pellet of the same size and shape, which in turn is larger than the $Z_{\mathrm{DR}}$ of a lower-density ice particle (e.g., graupel or snow aggregate) of the same size and shape. Because it is a ratio of the backscattered powers at $\mathrm{H}$ and $\mathrm{V}$ polarizations, $Z_{\mathrm{DR}}$ is independent of particle concentration and is not affected by absolute miscalibration of the radar transmitter or receiver. However, accuracy on the order of $0.1-0.2 \mathrm{~dB}$ is needed if $Z_{\mathrm{DR}}$ is to be used for quantitative purposes. Thus, biases introduced in the radar hardware can cause offsets that must be corrected first before quantitative use of $Z_{\mathrm{DR}}$ measurements (e.g., Zrnić et al. 2006a). $Z_{\mathrm{DR}}$ can be biased in the presence of anisotropic beam blockage (i.e., a tall, skinny tower that blocks more of the V-polarization wave than the $\mathrm{H}$-polarization wave, causing the downradial $Z_{\mathrm{DR}}$ to be strongly positively biased). Because the WSR-88D radars operate in a mode of simultaneous transmission of $\mathrm{H}$ and $\mathrm{V}$ polarization waves, cross coupling of the waves is possible for depolarizing media and antenna polarization errors (e.g., Ryzhkov and Zrnić 2007; Hubbert et al. 2010a,b). This will be described in more detail in Part III of this series, which discusses polarimetric radar data artifacts.

\section{1) RAIN}

Larger raindrops become deformed by aerodynamic drag and thus are more oblate than smaller raindrops (e.g., Pruppacher and Beard 1970; Pruppacher and Pitter 1971; Beard and Chuang 1987; Brandes et al. 2002; Thurai and Bringi 2005). Therefore, rainfall characterized by larger drop sizes will have larger observed $Z_{\mathrm{DR}}$, indicating more power received at $\mathrm{H}$ polarization than at $\mathrm{V}$ polarization. In rain, $Z_{\mathrm{DR}}$ tends to increase with increasing $Z_{H}$, as heavier rainfall is characterized by larger concentrations of bigger drops. An exception to this tendency is in the case of size sorting of raindrops (e.g., Kumjian and Ryzhkov 2009; 2012), whereupon certain parts of storms may be observed to have large $Z_{\mathrm{DR}}$ (indicating big, oblate drops) and relatively modest $Z_{H}$ (indicating those big 
drops are in low concentrations). Such size sorting is generally localized along the leading edge of precipitating systems and/or beneath updrafts. $Z_{\mathrm{DR}}$ varies with raindrop sizes and shapes but is independent of particle concentration, whereas $Z_{H}$ is directly proportional to particle concentration. Thus, for a given value of $Z_{H}$ in rain, there is a range of possible $Z_{\mathrm{DR}}$ values that can be observed (Fig. 2) depending on the drop size distribution (DSD). The DSD is influenced by many factors, including the storm's environment and microphysics. In general, for a given $Z_{\mathrm{H}}$ value, more tropical rainfall is associated with smaller raindrops (e.g., Maki et al. 2005; Ryzhkov et al. 2005a,c; Bringi et al. 2006; Tokay et al. 2008; Ryzhkov et al. 2011) and thus smaller $Z_{\mathrm{DR}}$ values, whereas continental rainfall tends to have larger $Z_{\mathrm{DR}}$, signifying bigger drops.

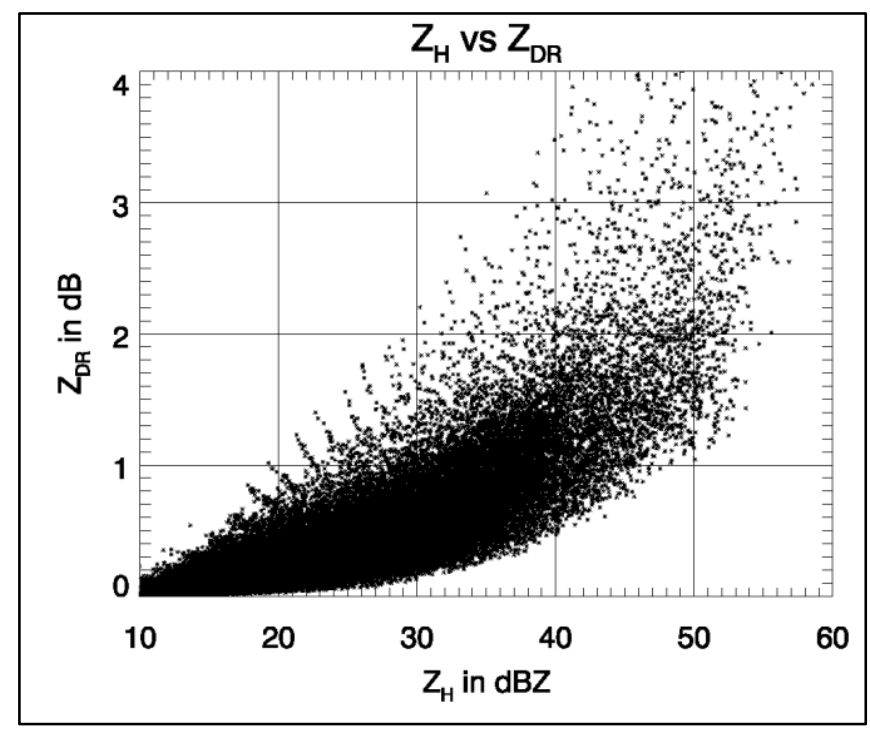

Figure 2. $Z_{H}$ and $Z_{\mathrm{DR}}$ calculated from 47144 drop size distributions observed by a 2D video disdrometer (e.g., Schönhuber et al. 1997; Schuur et al. 2001) in central Oklahoma. Computations assume raindrops are $20^{\circ} \mathrm{C}$, and are for $\mathrm{S}$ band (the operating frequency of the WSR-88D radars). The dataset includes a broad spectrum of precipitating systems, including stratiform and convective storms, as well as "tropical" and "continental" storms.

\section{2) HAIL AND GRAUPEL}

The intrinsic $Z_{\mathrm{DR}}$ of hail varies dramatically as a function of hailstone size, shape, and how much liquid water is located on or within the hailstone. If hail tumbles chaotically as it falls, the resulting measured $Z_{\mathrm{DR}}$ is close to zero, as the stones appear to be spherical in the statistical sense (e.g., Aydin et al. 1986; Bringi et al. 1986; Wakimoto and Bringi 1988). This applies for hailstones of any size. However, small nonzero $Z_{\mathrm{DR}}$ values measured in large hail well above the environmental $0^{\circ} \mathrm{C}$ level indicate some degree of alignment (e.g., Kumjian et al. 2010a; Picca and Ryzhkov 2012). In general, however, the $Z_{\mathrm{DR}}$ values of large hail are much lower than they are for rain of the same measured $Z_{H}$, providing the ability to use $Z_{H}$ and $Z_{\mathrm{DR}}$ measurements for the detection of hail (e.g., Aydin et al. 1986; Bringi et al. 1986; Ryzhkov et al. 2005a; Heinselman and Ryzhkov 2006).

For particles that are not small compared to the radar wavelength (Mie scatterers), the shape information provided by $Z_{\mathrm{DR}}$ can be ambiguous. For example, very large oblate hail [ $>5 \mathrm{~cm}$ ( 2 in) in diameter] can produce negative $Z_{\mathrm{DR}}$ values (e.g., Aydin and Zhao 1990; Balakrishnan and Zrnić 1990b; Kumjian et al. 2010b; Picca and Ryzhkov 2012). This strange behavior occurs because the stones are so large that complex resonance scattering effects become important, and the crossed-dipole antenna model of the particle is no longer valid.

As small hail melts, it acquires a shell or "torus" of liquid water (e.g., Rasmussen et al. 1984; Rasmussen and Heymsfield 1987). The presence of the liquid water not only increases the particle's effective refractive index, but tends to stabilize its wobbling. Both of these factors lead to increased $Z_{\mathrm{DR}}$. Indeed, $Z_{\mathrm{DR}}$ in small melting hail can match or exceed that of large raindrops (i.e., >3-4 dB). In contrast, larger hailstones tend to shed much of their excess water. This prevents the buildup of a torus, causing the water coating to remain quite thin. This causes the $Z_{\mathrm{DR}}$ of larger wet stones to be much lower. Again, very large oblate wet hail can produce negative $Z_{\mathrm{DR}}$ values owing to resonance scattering effects.

Graupel particles are formed by heavy riming of pre-existing ice particles such as snow crystals or frozen drops. As such, their density tends to be below that of solid ice but higher than that of snow aggregates. Therefore, the complex refractive index of graupel is larger than that of snow, but smaller than that of hail. The higher density of these particles means that $Z_{H}$ is larger than in snow and $Z_{\mathrm{DR}}$ is more sensitive to shapes than it is in snow aggregates, though far less sensitive than for wet particles. Most rimed particles are quasi-spherical, thus producing $Z_{\mathrm{DR}}$ near zero. However, conical-shaped graupel particles -not dissimilar in shape from a NASA Apollo Command Module - are frequently observed (e.g., Holroyd 1964; Magono and Lee 1966; Knight and Knight 1973). Such particles may produce slightly negative $Z_{\mathrm{DR}}$ (e.g., Aydin and Seliga 1984). Because 
riming is necessary to produce graupel particles, it is often found in the vicinity of updrafts (or some other source of supercooled liquid cloud water).

\section{3) SNOW AND ICE CRYSTALS}

The observed $Z_{\mathrm{DR}}$ in dry snow varies dramatically, depending on the crystal habits present within the radar sampling volume. Pristine ice crystals such as dendrites, plates, and needles are very anisotropic (i.e., have aspect ratios that are significantly different from 1.0). Thus, when these pristine ice crystals (which are usually oriented with their major axis horizontal) are the dominant contributors to the reflectivity factor within the radar volume, large positive $Z_{\mathrm{DR}}$ is possible. Note that vertical alignment of ice crystals can occur in strong electric fields; such vertical alignment produces negative $Z_{\mathrm{DR}}$ values. The exact value of $Z_{\mathrm{DR}}$ depends on the crystal density; solid ice particles such as hexagonal plates can have intrinsic $Z_{\mathrm{DR}}$ values larger than $6 \mathrm{~dB}$, in some cases even approaching 10 $\mathrm{dB}$ (e.g., Hogan et al. 2002), whereas the $Z_{\mathrm{DR}}$ in dendrites generally remains below about 4-5 dB. However, because of particle wobbling, imperfect shapes, and a mixture of crystal types usually present in clouds, observed $Z_{\mathrm{DR}}$ values in ice crystals usually do not exceed about 4-5 dB.

In contrast to the pristine ice crystals, large aggregates are observed to have very low $Z_{\mathrm{DR}}(<0.5$ $\mathrm{dB})$. This is primarily attributable to their very low density (usually $<0.2 \mathrm{~g} \mathrm{~cm}^{-3}$, compared to the density of solid ice of $0.92 \mathrm{~g} \mathrm{~cm}^{-3}$ ), which makes their exact shape less important from the radar's perspective. Additionally, increased fluttering of aggregates tends to keep $Z_{\mathrm{DR}}$ quite low. Note that, because of their large sizes compared to pristine crystals, snow aggregates tend to have larger $Z_{H}$ values. Observations of $Z_{H}$ increasing towards the ground coincident with $Z_{\mathrm{DR}}$ decreasing towards the ground are consistent with ongoing aggregation. In general, in dry snow, $Z_{H}$ and $Z_{\mathrm{DR}}$ are anticorrelated; higher $Z_{\mathrm{DR}}$ values typically are collocated with smaller $Z_{H}$ values (Fig. 3).

As snow begins to melt, the accumulation of liquid water produces a larger refractive index, which causes both $Z_{H}$ and $Z_{\mathrm{DR}}$ to increase. The well-known "bright band" signature associated with the melting layer is primarily because of this effect. For example, small, pristine crystals that begin to melt can produce very large $Z_{\mathrm{DR}}$ values (>6 dB; Schuur et al. 2012). Because $Z_{\mathrm{DR}}$ is independent of particle concentration, large $Z_{\mathrm{DR}}$ values in the melting layer are possible even with rather low $Z_{H}$. In such situations, $Z_{\mathrm{DR}}$ can be more efficient at detecting the melting layer than $Z_{H}$.

\section{4) NONMETEOROLOGICAL ECHOES}

Nonmeteorological scatterers are any targets within the radar sampling volume that are not precipitation particles. This can include biological scatterers (e.g., birds, insects, and bats), smoke and ash from fires or volcanoes, military chaff, ground and sea clutter, and tornadic debris, among others. Biological targets tend to have elongated bodies, so the measured $Z_{\mathrm{DR}}$ in birds and insects is often quite high (e.g., Zrnić and Ryzhkov 1998) - usually larger than most meteorological targets. Insects especially can be observed to have $Z_{\mathrm{DR}}$ values in excess of 6-7 $\mathrm{dB}$. In the case of bird migrations, there may be an azimuthal dependence of the measured $Z_{\mathrm{DR}}$ that corresponds to the different viewing angles of the bird's geometry.

Observed $Z_{\mathrm{DR}}$ values in smoke and ash are variable, but can be very large $(>6 \mathrm{~dB}$; see Melnikov et al. 2008, 2009). Similarly, military chaff, ground clutter, and sea clutter can have variable $Z_{\mathrm{DR}}$, but can have positive or negative values that exceed the range of values for most hydrometeors. For example, sea clutter has been observed to have large negative $Z_{\mathrm{DR}}$ values (e.g., Long 2001; Ryzhkov et al. 2002). The sign of $Z_{\mathrm{DR}}$ in sea clutter depends on the radar viewing angle of the water waves.

Tornadic debris tends to be irregularly shaped, but often tumbles. This causes $Z_{\mathrm{DR}}$ to have near-zero values. However, there are some observations of negative $Z_{\mathrm{DR}}$ in tornadic debris (e.g., Ryzhkov et al. 2005b; Kumjian and Ryzhkov 2008; Bodine et al. 2013). It is unclear what type of debris causes such large negative values, but the fact that values are nonzero indicates some degree of alignment (i.e., random orientation would produce $Z_{\mathrm{DR}}$ of $0 \mathrm{~dB}$ ). Note that large pieces of debris (non-Rayleigh scatterers) do not have to be prolate in shape and/or vertically aligned to produce negative values, owing the complexity of resonance scattering off such large particles.

\section{b. Differential propagation phase shift, $\Phi_{D P}$, and spe- cific differential phase, $K_{D P}$}

As EM radiation propagates through precipitation, it acquires an additional phase shift compared to EM radiation traveling the same distance through air. If the precipitation is nonspherical, such as oblate raindrops, then the amount of phase shift acquired is different 


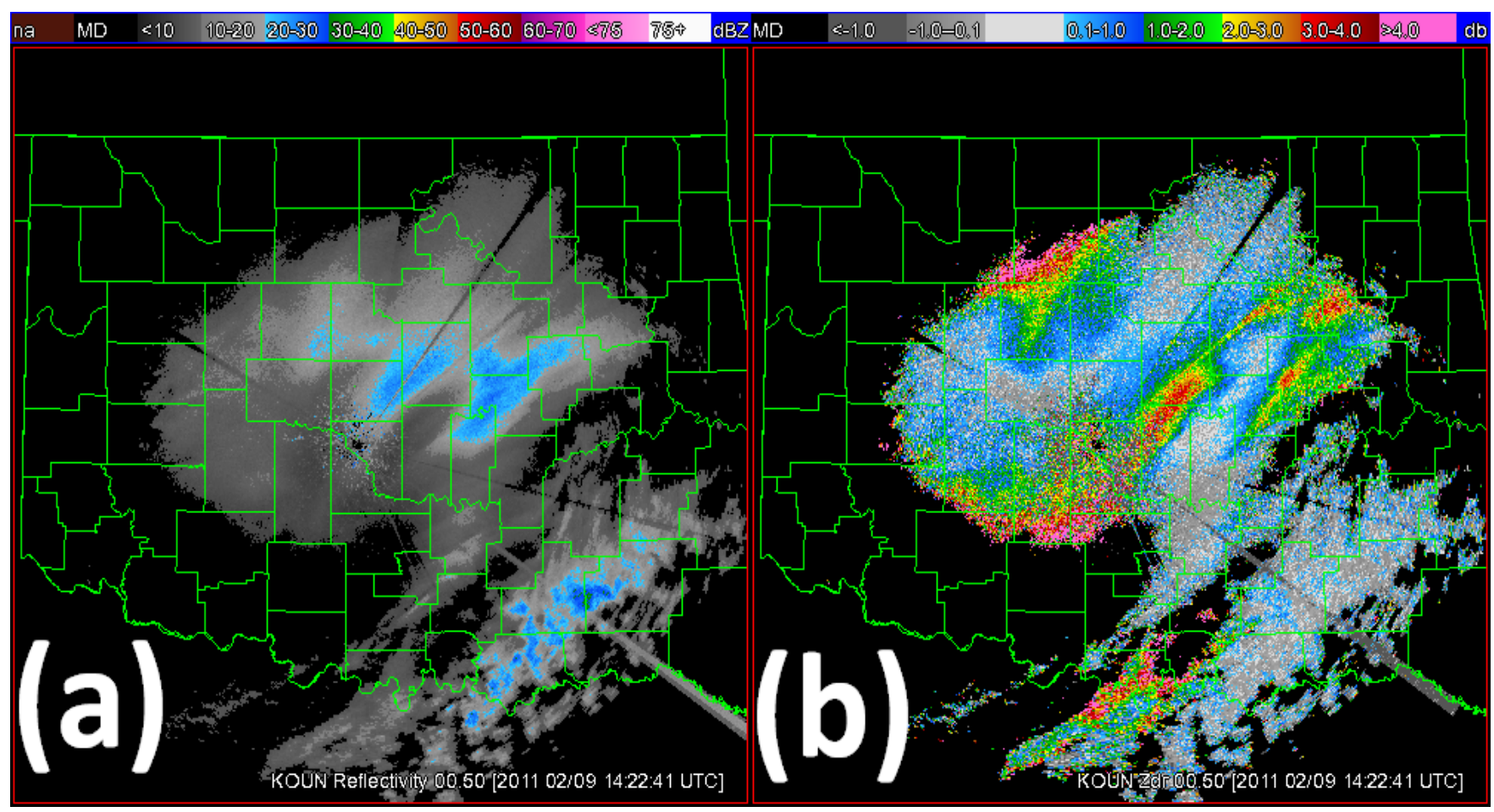

Figure 3. Display of (a) $Z_{H}$ and (b) $Z_{\mathrm{DR}}$, from a winter storm in central OK at 1423 UTC 9 February 2011 , taken by the polarimetric WSR$88 \mathrm{D}$ radar KOUN (Norman) at $0.5^{\circ}$ elevation.

between $\mathrm{H}$ and $\mathrm{V}$ polarizations. For oblate particles, this can be thought of as the H-polarization wave slowing relative to the $\mathrm{V}$-polarization wave because it is encountering more of the drops, which are larger in their horizontal dimension. The resulting difference in phase shift between $\mathrm{H}$ and $\mathrm{V}$ polarizations is known as the differential propagation ${ }^{4}$ phase shift, $\Phi_{\mathrm{DP}}$.

$\Phi_{\mathrm{DP}}$ is proportional to the number concentration of particles and tends to increase with increasing particle size. Because $\Phi_{\mathrm{DP}}$ is a phase measurement, it is not affected by attenuation, partial beam blockage, or radar miscalibration, and is not biased by noise. For these reasons, it is an attractive variable to use for attenuation correction and quantitative precipitation estimation. Often more useful for meteorologists is half $^{5}$ the range derivative of $\Phi_{\mathrm{DP}}$, known as the

\footnotetext{
4 The actual measured differential phase shift is a combination of the differential propagation phase, the radar system differential phase offset, and any differential phase imparted by backscatter from non-Rayleigh scatterers. For simplicity, herein we consider just the propagation component.

5 Because the differential propagation phase shift accumulates over the two-way path through the precipitation and back, only half is taken for $K_{\mathrm{DP}}$ to characterize the precipitation properties along the propagation path.
}

specific differential phase $\left(K_{\mathrm{DP}}\right)$. This provides a measure of the amount of differential phase shift per unit distance (usually given in units of degrees per $\mathrm{km}$ ) along the radial direction. Thus, it is useful for locating regions of heavy precipitation (Fig. 4). Regions of high $K_{\mathrm{DP}}$ often overlap regions of high $Z_{H}$; however, the main difference between enhancements in $Z_{H}$ and enhancements in $K_{\mathrm{DP}}$ is that $Z_{H}$ is affected by liquid and frozen particles, whereas $K_{\mathrm{DP}}$ is mainly affected by the presence of liquid water (more on this below). However, $K_{\mathrm{DP}}$ can be difficult to estimate in light rain, as well as in the presence of nonuniform beam filling (Ryzhkov and Zrnić 1998; Gossett 2004; Ryzhkov 2007; see Part III) and in the presence of non-Rayleigh scatterers such as very large hail.

\section{1) RAIN}

The use of $K_{\mathrm{DP}}$ for quantitative precipitation estimation was proposed by Seliga and Bringi (1978), Jameson et al. (1985a), and Sachidananda and Zrnić $(1986,1987) . K_{\mathrm{DP}}$ is positive in rain because raindrops are oblate, causing the H-polarization wave to acquire more of a phase shift than the V-polarization wave. $K_{\mathrm{DP}}$ is particularly useful for rainfall estimation in cases when hail is mixed with rain (e.g., Balakrishnan 


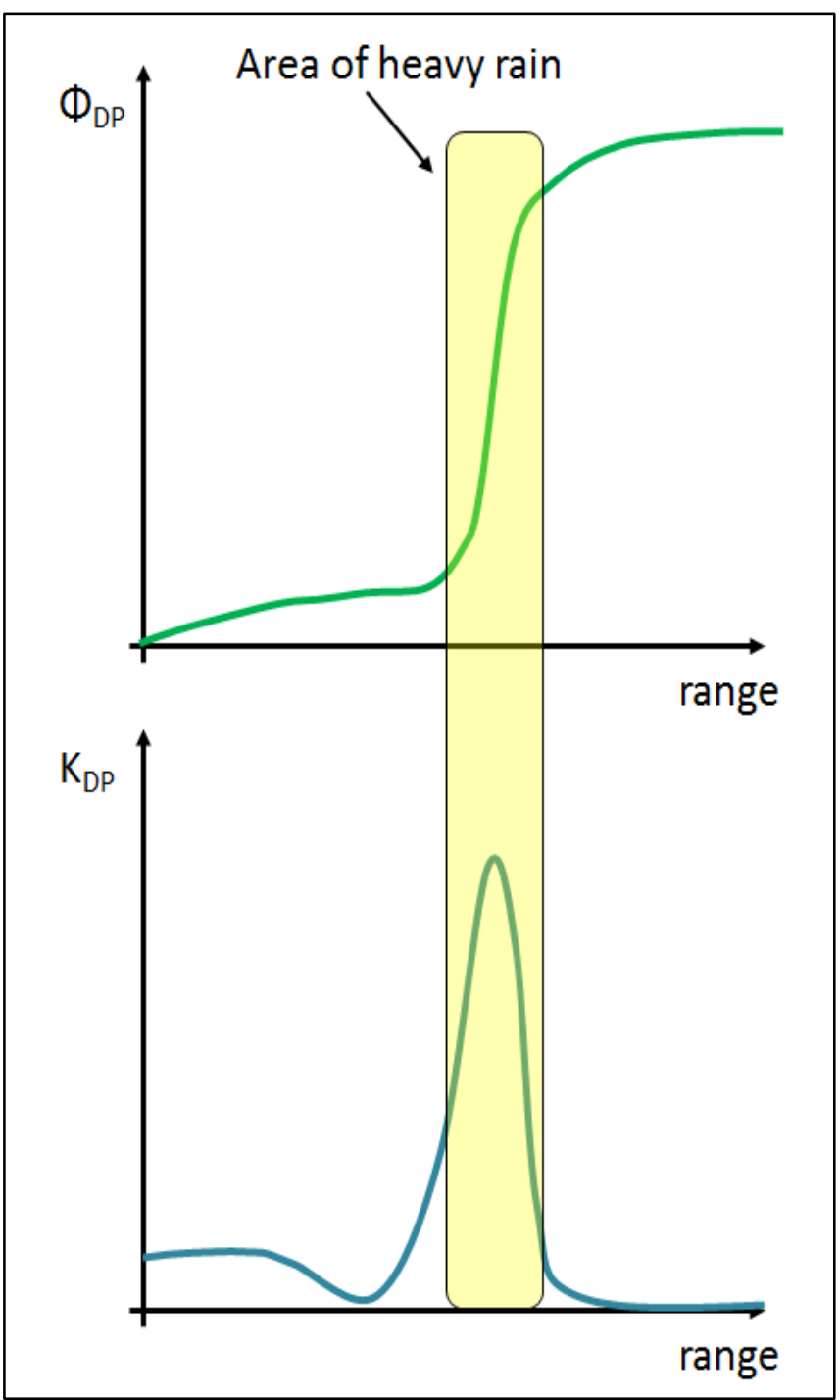

Figure 4. Schematic illustrating the range profile of $\Phi_{\mathrm{DP}}$ (top panel), which increases dramatically in an area of heavy rain (highlighted in yellow). The bottom panel corresponds to the $K_{\mathrm{DP}}$, which is maximized in the heavy rain.

and Zrnić 1990a; Giangrande and Ryzhkov 2008). This is because $K_{\mathrm{DP}}$ is not affected by tumbling particles, for which the $\mathrm{H}$ - and V-polarization waves acquire the same amount of phase shift. In addition, $K_{\mathrm{DP}}$ is nearly linearly related to rainfall rate (e.g., Sachidananda and Zrnić 1987), and can be considered a good measure of the amount of liquid water in the radar sampling volume in warm-season precipitation. Though estimates of $K_{\mathrm{DP}}$ can be noisy in light rain, use of $K_{\mathrm{DP}}$ for estimates of long-term accumulations of light rain have proven accurate (Borowska et al. 2011), because the noisy, statistical fluctuations average out to zero for longer time periods. This is analogous to the results of Ryzhkov et al. (2005c), who found that rainfall estimates with $K_{\mathrm{DP}}$ show larger improvements over conventional algorithms when averaged over larger spatial regions.

\section{2) HAIL AND GRAUPEL}

$K_{\mathrm{DP}}$ is zero in spherical or tumbling particles, such as dry hail. However, not all hailstones are randomly tumbling, and thus nonzero differential phase shifts are possible in nonspherical hailstones. In fact, negative $K_{\mathrm{DP}}$ values are possible in very large hail; however, because these stones are non-Rayleigh scatterers, they may produce a significant component of differential phase shift upon backscatter. Such backscatter differential phase shift, denoted as $\delta$, is superposed on the propagation differential phase shift, and thus estimating $K_{\mathrm{DP}}$ becomes very difficult. Some techniques have been developed to separate $\delta$ and the propagation phase shift component (e.g., Hubbert and Bringi 1995). $K_{\mathrm{DP}}$ can be enhanced when there is a significant addition of liquid water on melting hailstones. However, again owing to the difficulty in estimating $K_{\mathrm{DP}}$ for non-Rayleigh scatterers, $K_{\mathrm{DP}}$ values may not be reliable in large melting hail. Large values of $K_{\mathrm{DP}}$ are possible in small melting hail mixed with rain, as the smaller melting hailstones acquire significant liquid water coats (e.g., Rasmussen et al. 1984). Such substantial liquid water shells cause the small melting hailstones to be sensed as "giant raindrops" by radar. When found in large concentrations, small melting hail mixed with rain can produce very large $K_{\mathrm{DP}}$ values (>6-8 deg km $\mathrm{k}^{-1}$ ).

Because dry graupel has such a low complex refractive index (compared to liquid water), the contribution of dry graupel particles to $K_{\mathrm{DP}}$ is negligible. Similar to melting hail, melting graupel can exhibit positive $K_{\mathrm{DP}}$ values.

\section{3) SNOW AND ICE CRYSTALS}

Large dry snow aggregates have nearly zero intrinsic $K_{\mathrm{DP}}$. In other words, aggregates are nearly "invisible" to the propagation differential phase shift. Because of the low radial slope of $\Phi_{\mathrm{DP}}$ through snow aggregates, $K_{\mathrm{DP}}$ estimates from measurements may be very noisy in dry snow. However, pristine ice crystals such as hexagonal plates, dendrites, and needles in sufficiently high concentrations may produce positive $K_{\mathrm{DP}}$ values as large as $0.5 \mathrm{deg} \mathrm{km}^{-1}$ or more (e.g., Kennedy and Rutledge 2011; Andrić et al. 2013; Bechini et al. 2013; Schneebeli et al. 2013). Whereas $Z_{H}$ is affected by the presence of snow aggregates, $K_{\mathrm{DP}}$ 
can still be used to detect the presence of the pristine ice crystals mixed with aggregates. Strong electric fields in the ice portions of convective clouds can align small ice crystals in the horizontal or vertical, producing positive or negative $K_{\mathrm{DP}}$ values aloft (e.g., Caylor and Chandrasekar 1996; Zrnić and Ryzhkov 1999; Ryzhkov and Zrnić 2007).

Much like melting hail, melting snowflakes can produce an enhancement of $K_{\mathrm{DP}}$. However, the presence of larger wet aggregates can cause nonzero backscatter differential phase shift $\delta$ (Zrnić et al. 1993; Trömel et al. 2013), that with the associated reductions in the correlation coefficient $\rho_{\text {hv }}(C C)$, make it difficult to estimate $K_{\mathrm{DP}}$ reliably in the melting layer.

\section{4) NONMETEOROLOGICAL ECHOES}

Nonmeteorological targets often exhibit noisy $K_{\mathrm{DP}}$, as the low $\rho_{\mathrm{hv}}(C C)$ associated with such targets increases the variability or fluctuations of the propagation differential phase $\Phi_{\mathrm{DP}}$. In addition, some biological scatterers such as birds produce substantial differential phase shift upon backscatter $\delta$. Thus, low $\rho_{\text {hv }}(C C)$ and wild fluctuations in the measured differential phase shift make $K_{\mathrm{DP}}$ estimates unreliable in "clear air" returns. For this reason, $K_{\mathrm{DP}}$ is not computed in regions of substantially reduced $\rho_{\mathrm{hv}}(C C)$ in operational displays.

\section{c. Co-polar correlation coefficient, $\rho_{h v}$ (or CC)}

The co-polar correlation coefficient between $\mathrm{H}$ and $\mathrm{V}$-polarization waves is known as $\rho_{\mathrm{hv}}$ in the scientific literature, or $C C$ in the operational Advanced Weather Interactive Processing System (AWIPS) displays (they are used interchangeably herein). It was introduced in the 1980s by Sachidananda and Zrnić (1985) and Jameson and Mueller (1985b). $C C$ or $\rho_{\mathrm{hv}}$ is a measure of the diversity of how each scatterer in the sampling volume contributes to the overall $\mathrm{H}$ - and Vpolarization signals. This diversity includes any physical characteristic of the scatterers that affects the returned signal amplitude and phase. Thus, when there exists a large variety in the types, shapes, and/or orientations of particles within the radar sampling volume, $C C$ is decreased. Note that a diversity of sizes does not affect $\rho_{\mathrm{hv}}(C C)$ unless the shape of the particles varies across the size spectrum. In addition to reduced values with increased diversity of the physical characteristics of particles, $C C$ can be significantly reduced in the presence of non-Rayleigh scatterers, owing to variability in the backscattered differential phase $^{6}$ within the sampling volume. Imperfections in the radar hardware can produce reductions in $C C$ as well.

In contrast, more uniform scatterers tend to produce $C C$ near 1.0. Spherical particles of any size will produce $C C=1.0$ because they each contribute identically to the signals at $\mathrm{H}$ and $\mathrm{V}$ polarizations. Values of $C C>1.0$ are sometimes observed at the periphery of precipitation echoes. These values are not physical and are a result of improper correction for low signal-to-noise ratio. They are retained in AWIPS displays to alert meteorologists that at the edges of some echoes, the data quality is reduced. Other regions where the measured $C C$ can be reduced below its intrinsic value include those affected by nonuniform beam filling (Ryzhkov 2007; see Part III). CC is independent of particle concentration and is immune to radar miscalibration, attenuation or differential attenuation, and beam blockage.

\section{1) RAIN}

At the operating frequency of WSR-88D radars (S band), pure rain produces very high values of $C C$ $(>0.98)$. It is slightly $<1.0$ because the shape of raindrops changes across the spectrum (larger drops are more oblate than smaller drops), and because raindrops exhibit some slight wobbling as they fall. Heavy rain tends to have slightly lower $C C$ than light rain, but very light rain and drizzle should have $C C$ near 1.0 (because all drops are small and thus close to spherical in shape).

\section{2) HAIL AND GRAUPEL}

Pure dry hail aloft can produce very high $C C$, similar to what is expected in pure rain or pure dry snow aggregates. However, wet hail can produce low $C C(<0.95)$ both aloft and at low levels, making it useful to distinguish between pure rain and areas of hail mixed with rain. Very large hail can produce dramatic decreases in $C C(<0.85)$, especially in the prime wet-growth region between about -10 and $-20^{\circ} \mathrm{C}$ (e.g., Dennis and Musil 1973; Nelson 1983; Picca and Ryzhkov 2012), as well as near the surface. This may be because of irregular shapes (such as lobes or spikes) that can lead to substantially reduced $C C$

\footnotetext{
${ }^{6}$ Rayleigh scatterers have negligible backscatter differential phase, whereas resonance scatterers can have appreciable nonzero values. Thus, resonance scatterers add to the diversity of differential phase within the radar sampling volume, reducing $C C$.
} 
(e.g., Balakrishnan and Zrnić 1990b). Such irregularities are produced in wet growth, which is very efficient at producing the larger hailstones. It is important to note that reduced $C C$ values at low levels and hail size do not exhibit a direct relation, as the size of particles alone does not affect $C C$.

Dry graupel particles, because they tend to be fairly uniform in shape, produce relatively large $C C$ values. Analogous to melting hail, melting or wet graupel can produce reductions in $C C$.

\section{3) SNOW AND ICE CRYSTALS}

In general, dry snow aggregates produce very high values of $C C(>0.97)$. This is because their very low density tends to counteract their irregular shapes and increased wobbling. In some cases, a tangible reduction in $C C$ (values < 0.96 ) is possible in pristine ice crystals such as needles and plates (Fig. 5). This is because of their highly nonspherical shapes, that when combined with no preferred azimuthal orientation and slight wobbling, lead to a diversity of "apparent" particle shapes from the perspective of the radar.

Melting of snowflakes leads to a reduction of $C C$ values $(<0.90)$. The addition of liquid meltwater on the particles accentuates the pre-existing variability in particle shapes and orientations by giving them a larger complex relative permittivity. Additionally, aggregation of melting snowflakes may be large enough to produce Mie scattering effects (Zrnić et al. 1993; Trömel et al. 2013). Because of these factors, the melting layer "bright band" signature is often most evident in $C C$ (Fig. 6). Brandes and Ikeda (2004) and Giangrande et al. $(2005,2008)$ have exploited this type of signature for automated melting layer detection algorithms, including the one implemented in the WSR-88D radar algorithm suite (see Part II).

\section{4) NonmeteorologicAl ECHOES}

Nonmeteorological scatterers generally produce very low $C C$, much lower $(<0.80)$ than expected in precipitation. This makes $C C$ especially useful for discriminating between precipitation particles and other scatterers. Such nonmeteorological scatterers include military chaff (Zrnić and Ryzhkov 2004), smoke and ash from fires or volcanoes (e.g., Melnikov et al. 2008, 2009; Jones et al. 2009; see Fig. 7), biological scatterers such as insects, birds, and bats (Zrnić and Ryzhkov 1998; Ryzhkov et al. 2005a; Bachmann and Zrnić 2007, 2008), sea clutter (Ryzhkov et al. 2002), dust, and tornadic debris

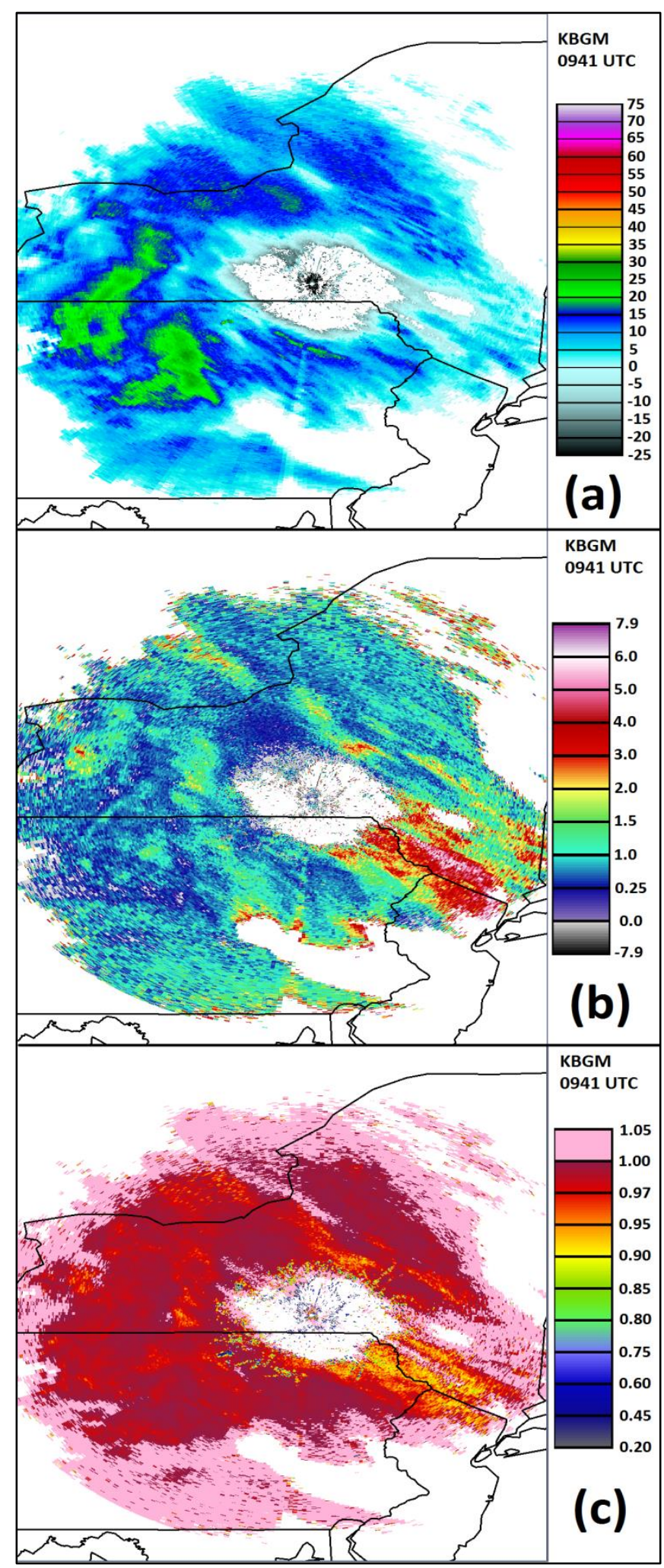

Figure 5. $0.5^{\circ}$ elevation angle PPI scan from the polarimetric WSR-88D radar near Binghamton, NY (KBGM). Data were collected at 0941 UTC 28 January 2013. Fields shown are (a) $Z_{H}$, (b) $Z_{\mathrm{DR}}$, and (c) $\rho_{\mathrm{hv}}$ or $C C$. Note the collocated regions of high $Z_{\mathrm{DR}}$ and reduced $C C\left(\rho_{\mathrm{hv}}\right)$, indicative of pristine nonspherical crystals. 


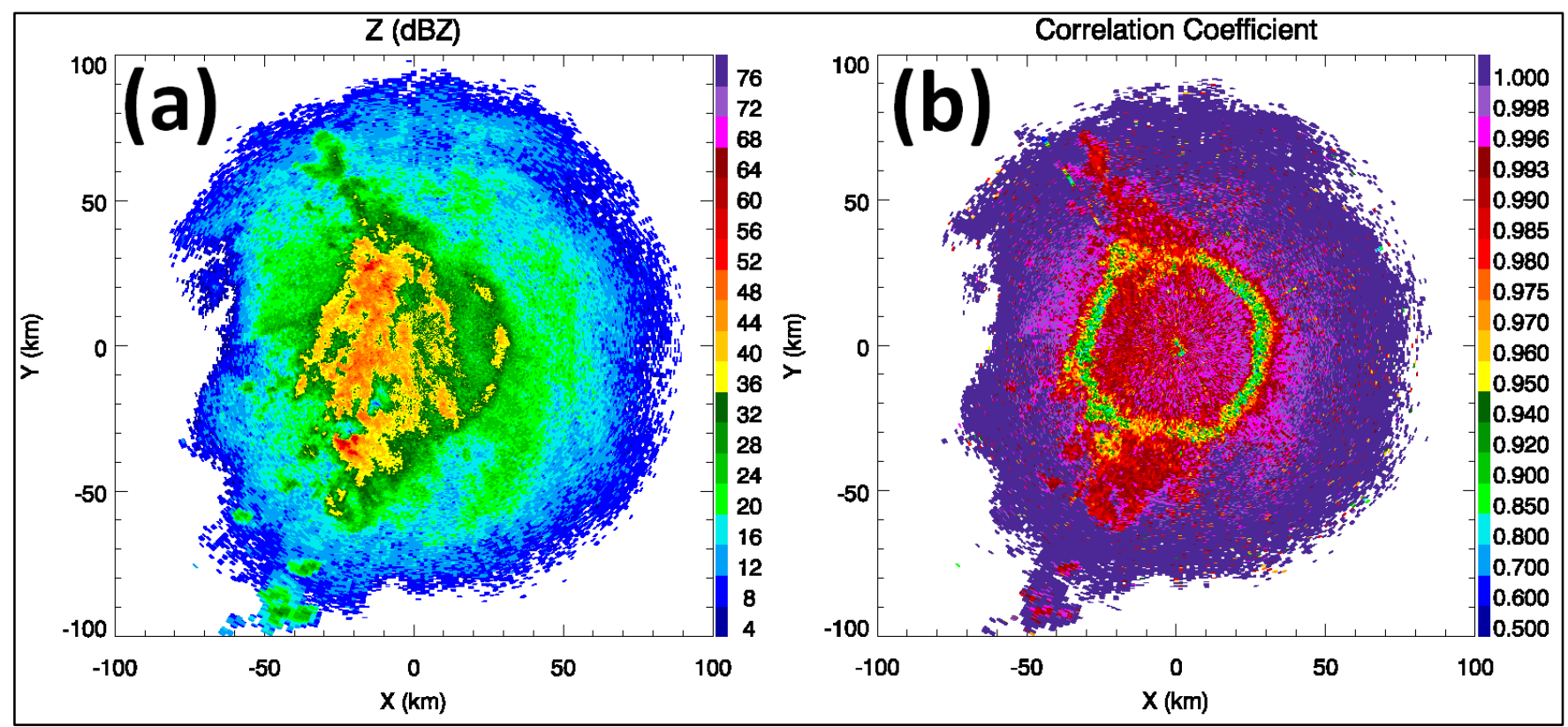

Figure 6. Example of the melting layer bright band in (a) $Z_{H}$ and (b) $C C$ or $\rho_{\mathrm{hv}}$. Data are from 0856 UTC 19 August 2007 , collected by the polarimetric prototype WSR-88D radar in Norman, $\mathrm{OK}(\mathrm{KOUN})$, at $8.0^{\circ}$ elevation.

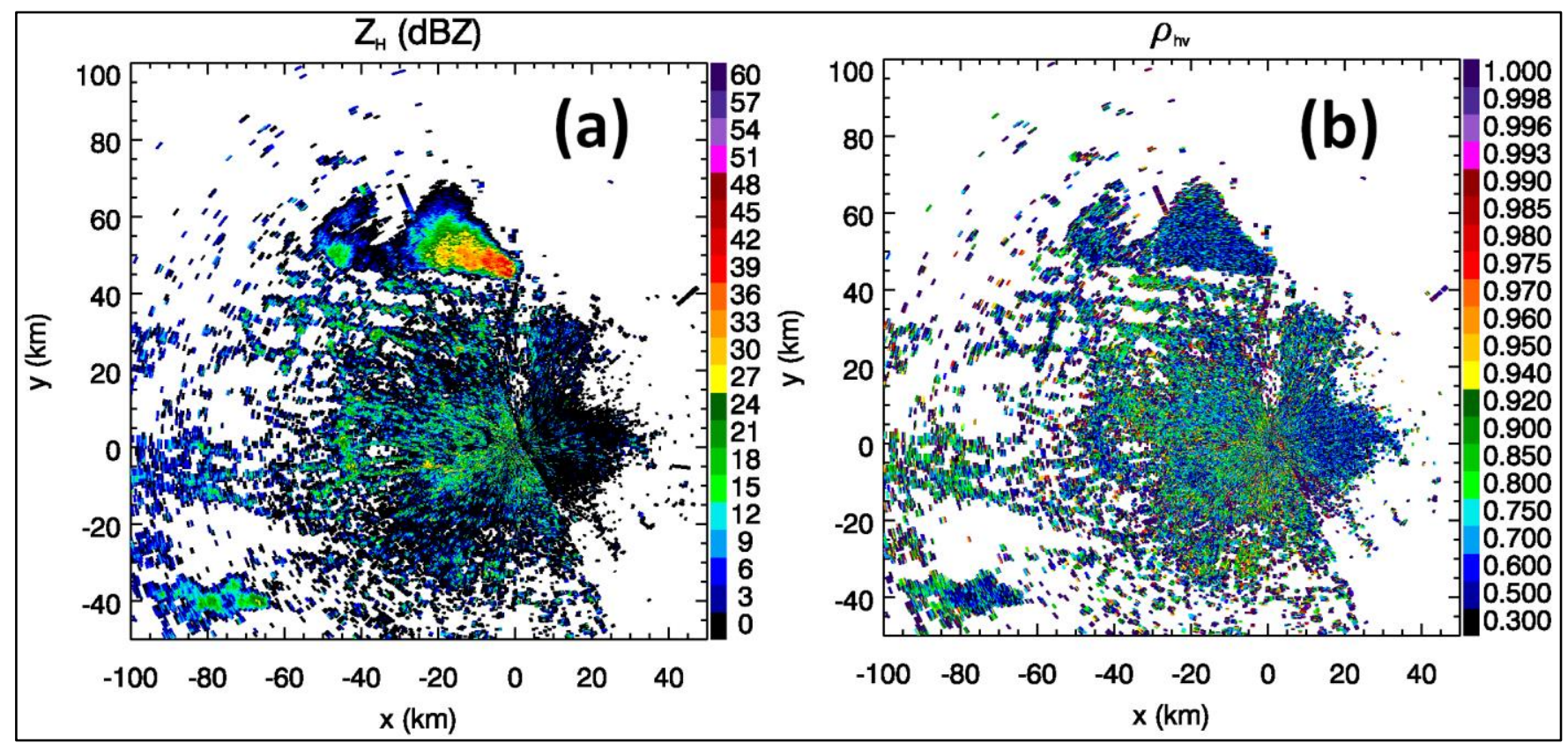

Figure 7. Display of (a) $Z_{H}$ and (b) $\rho_{\mathrm{hv}}(C C)$ from the polarimetric WSR-88D radar near Melbourne, FL (KMLB), taken at 2114 UTC 31 January 2012 from the $0.5^{\circ}$ elevation scan. The smoke and ash from the grassfire north of the radar are clearly identified by very low $\rho_{\mathrm{hv}}$ $(C C)$ values $(<0.50)$. The centroid of the grassfire echo is located at approximately $x=-5 \mathrm{~km}, \mathrm{y}=50 \mathrm{~km}$.

(Ryzhkov et al. 2005b; Bodine et al. 2013). The latter is especially important for operational meteorologists, as will be discussed in Part II. Note that man-made clutter targets such as buildings, water towers, and wind turbines can produce low $C C$ values, though the distribution of observed values exhibits some overlap with the high values that are characteristic of precipitation (e.g., Zrnić et al. 2006b).

\section{Summary}

In this first part of the review series, the polarimetric radar variables have been introduced and de- 
scribed. These variables are now available to meteorologists following the upgrade of the WSR-88D radar network and include the differential reflectivity $Z_{\mathrm{DR}}$, the differential propagation phase shift $\Phi_{\mathrm{DP}}$ and half its range derivative, specific differential phase $K_{\mathrm{DP}}$, and the co-polar correlation coefficient $C C\left(\rho_{\mathrm{hv}}\right)$. Emphasis was placed on the physical meaning of these new variables in precipitation and nonmeteorological ech- oes, as well as on providing a review of some of the scientific literature of interest. Appendix A provides a summary of the range of S-band values possible for different precipitation and nonprecip-itation echoes. Table 1 provides a summary of each polarimetric variable and whether they are impacted by various factors such as attenuation, particle density, size distribution variability, etc.

Table 1. Summary of dual-polarization moments and variables and whether they are affected by a number of factors. Listed variables are horizontal polarization reflectivity $Z_{H}$, Doppler velocity $V_{r}$, Doppler spectrum width $W$, differential reflectivity $Z_{\mathrm{DR}}$, specific differential phase $K_{\mathrm{DP}}$, and co-polar correlation coefficient $C C\left(\rho_{\mathrm{hv}}\right)$.

\begin{tabular}{|c|c|c|c|c|c|}
\hline & $\begin{array}{c}\text { Affected by attenuation/ } \\
\text { differential attenuation? }\end{array}$ & $\begin{array}{c}\text { Affected by partial } \\
\text { beam blockage? }\end{array}$ & Requires calibration? & $\begin{array}{c}\text { Affected by particle } \\
\text { density? }\end{array}$ & $\begin{array}{c}\text { Affected by resonance } \\
\text { scattering? }\end{array}$ \\
\hline $\boldsymbol{Z}_{\boldsymbol{H}}$ & Yes & Yes & Yes & Yes & No \\
\hline $\boldsymbol{V}_{\boldsymbol{r}}$ & No & No & No & No & No \\
\hline $\boldsymbol{W}$ & No & No & Yes & Yes & Yes \\
\hline $\boldsymbol{Z}_{\mathrm{DR}}$ & Yes & Yes & No & Yes \\
\hline $\boldsymbol{K}_{\mathrm{DP}}$ & No & No & No & Yes* & Yes \\
\hline $\boldsymbol{C} \boldsymbol{C}\left(\boldsymbol{\rho}_{\mathrm{hv}}\right)$ & No & No & Affected by DSD \\
& variability? & Biased by noise (low \\
SNR)?
\end{tabular}

* For a given set of particles in the sampling volume, increasing their density (and/or relative permittivity) amplifies the diversity present, decreasing $\rho_{\mathrm{hv}}$ $(C C)$.

** Strictly speaking, $Z_{H}$ can be biased by depolarization, though the effect is negligible compared to the effects on $Z_{\mathrm{DR}}$ and $K_{\mathrm{DP}}$ (e.g., Ryzhkov 2007).

Armed with a sufficient understanding of the physical meaning of the different polarimetric radar variables, Part II of this series will review and explore the meteorological applications of polarimetric radar measurements in warm- and cold-season precipitation. Part III reviews the most common artifacts observed in dual-polarization radar data.

Acknowledgments. The initial idea and encouragement for this review series was from Dr. Matthew Bunkers (NWS Rapid City); I am grateful to him for spearheading this project, as well as for reviewing drafts of the manuscripts at various stages. The project would not be possible without the guidance from - and many, many discussions with - the scientists at the National Severe Storms Laboratory, especially Dr. Alexander Ryzhkov. Additionally, the NWS Warning Decision Training Branch (WDTB) is thanked for useful discussions and meetings, notably Jami Boettcher, Clark Payne, and Paul Schlatter. Joey Picca (NWS New York), Scott Ganson (NWS Radar Operations Center) and
Dr. John Hubbert (NCAR) are thanked for useful comments on the manuscript. Reviews by Professor Paul Smith (South Dakota School of Mines and Technology) and Paul Schlatter (NWS Program Coordination Office) helped improve the quality of the manuscript and are greatly appreciated. Jon Zeitler (NWS Austin/San Antonio) provided constructive suggestions in the technical editing stage. Support for the author comes from the National Center for Atmospheric Research (NCAR) Advanced Study Program. NCAR is sponsored by the National Science Foundation.

\section{APPENDIX A}

\section{Ranges of the Polarimetric Radar Variables for Different Scatterers}

Figures A1-A4 demonstrate approximate ranges of Sband values for each polarimetric radar variable in different types of precipitation (rain, hail/graupel, and snow/ice) and nonmeteorological scatterers. Note that these are not meant to be firm boundaries; rather, they simply exhibit the ap- 


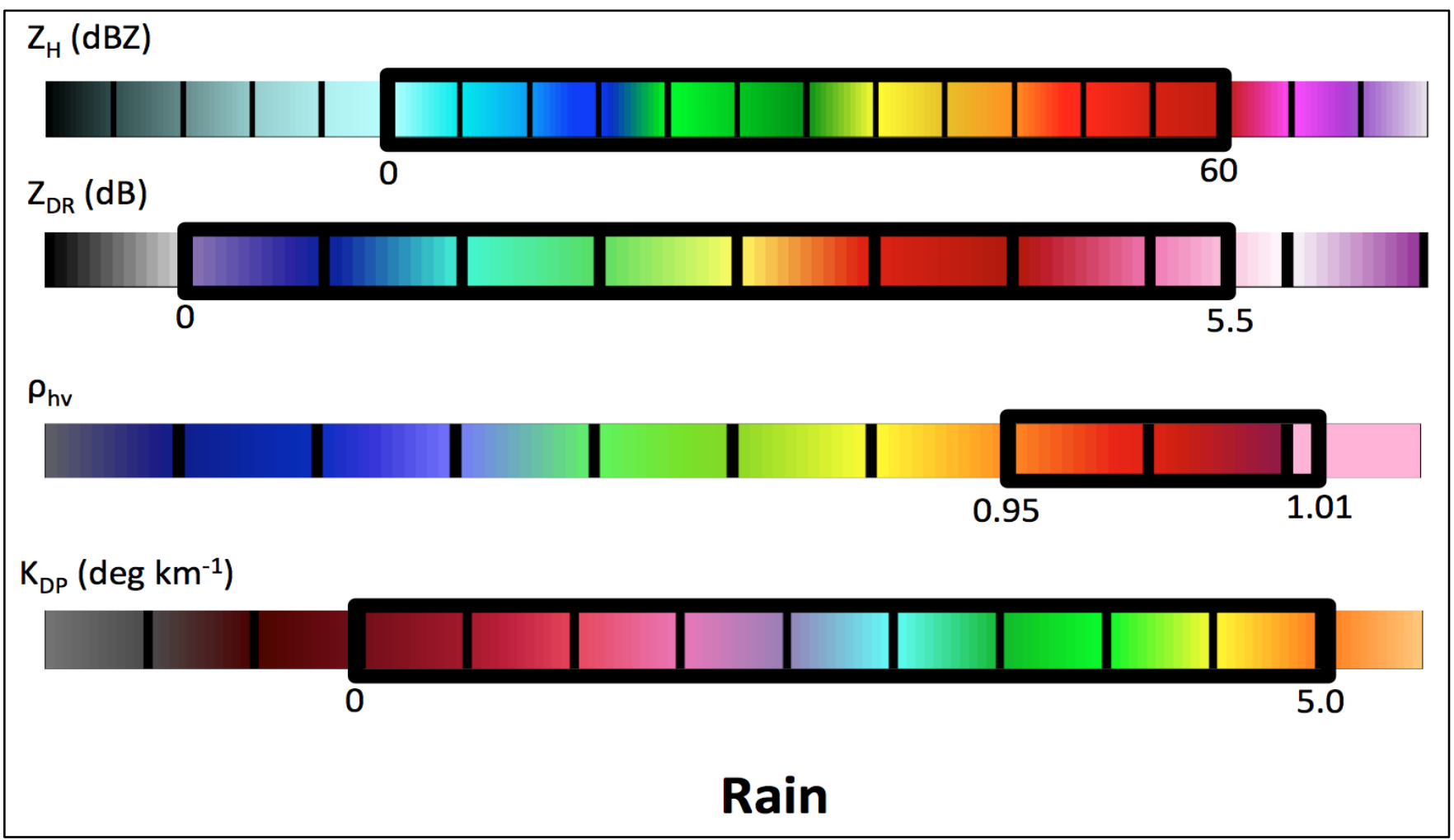

Figure A1. Approximate ranges of S-band values of each polarimetric variable $\left(Z_{H}, Z_{\mathrm{DR}}, \rho_{\mathrm{hv}}\right.$ or $C C$, and $\left.K_{\mathrm{DP}}\right)$ for rain. Here, the "rain" category includes rainfall of any intensity, from drizzle to intense convective rain, as well as the "big drops" category.

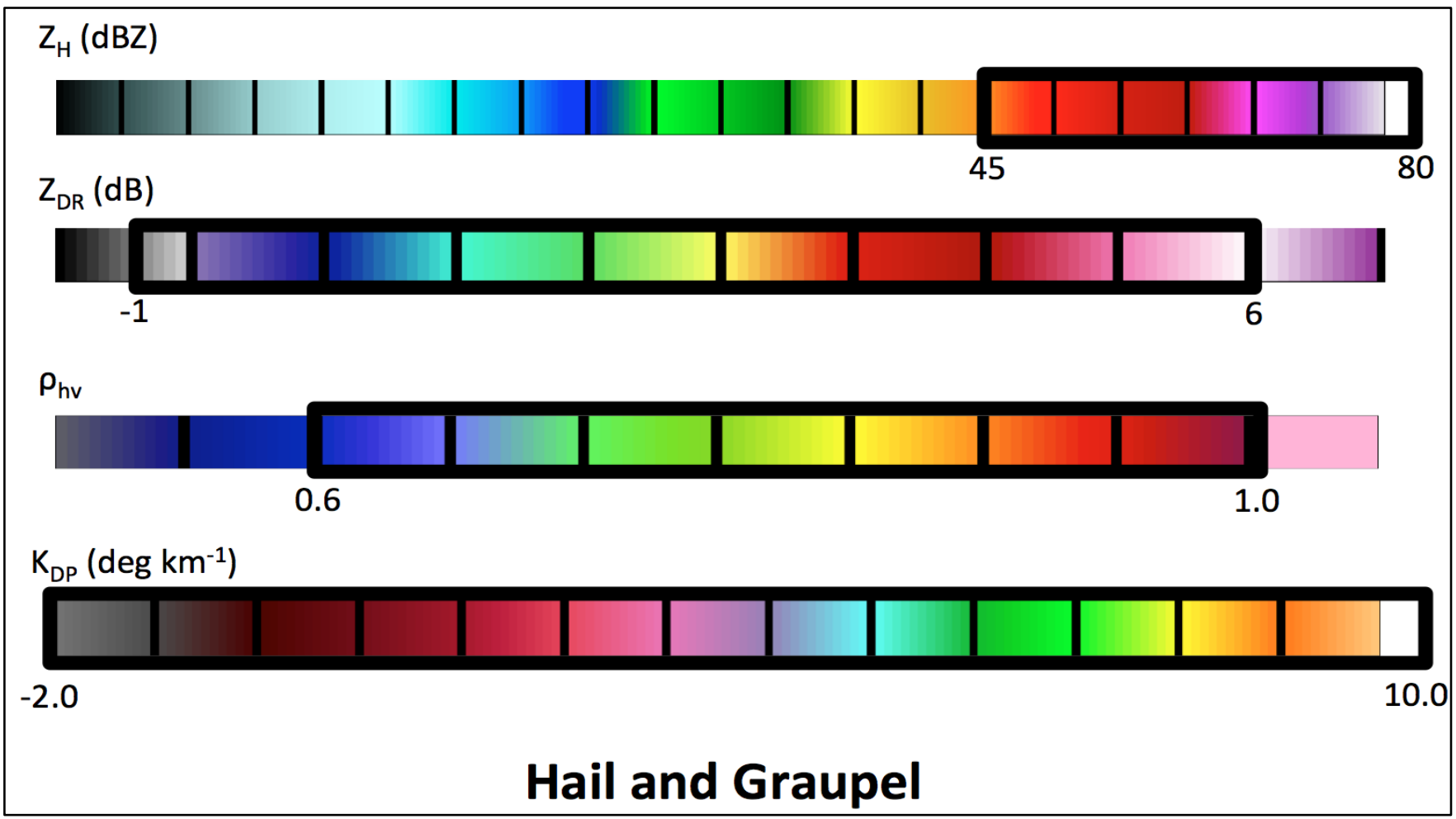

Figure A2. Approximate ranges of $S$-band values of each polarimetric variable $\left(Z_{\mathrm{H}}, Z_{\mathrm{DR}}, \rho_{\mathrm{hv}}\right.$ or $C C$, and $\left.K_{\mathrm{DP}}\right)$ for hail and graupel. Here, we consider both dry and melting particles. 


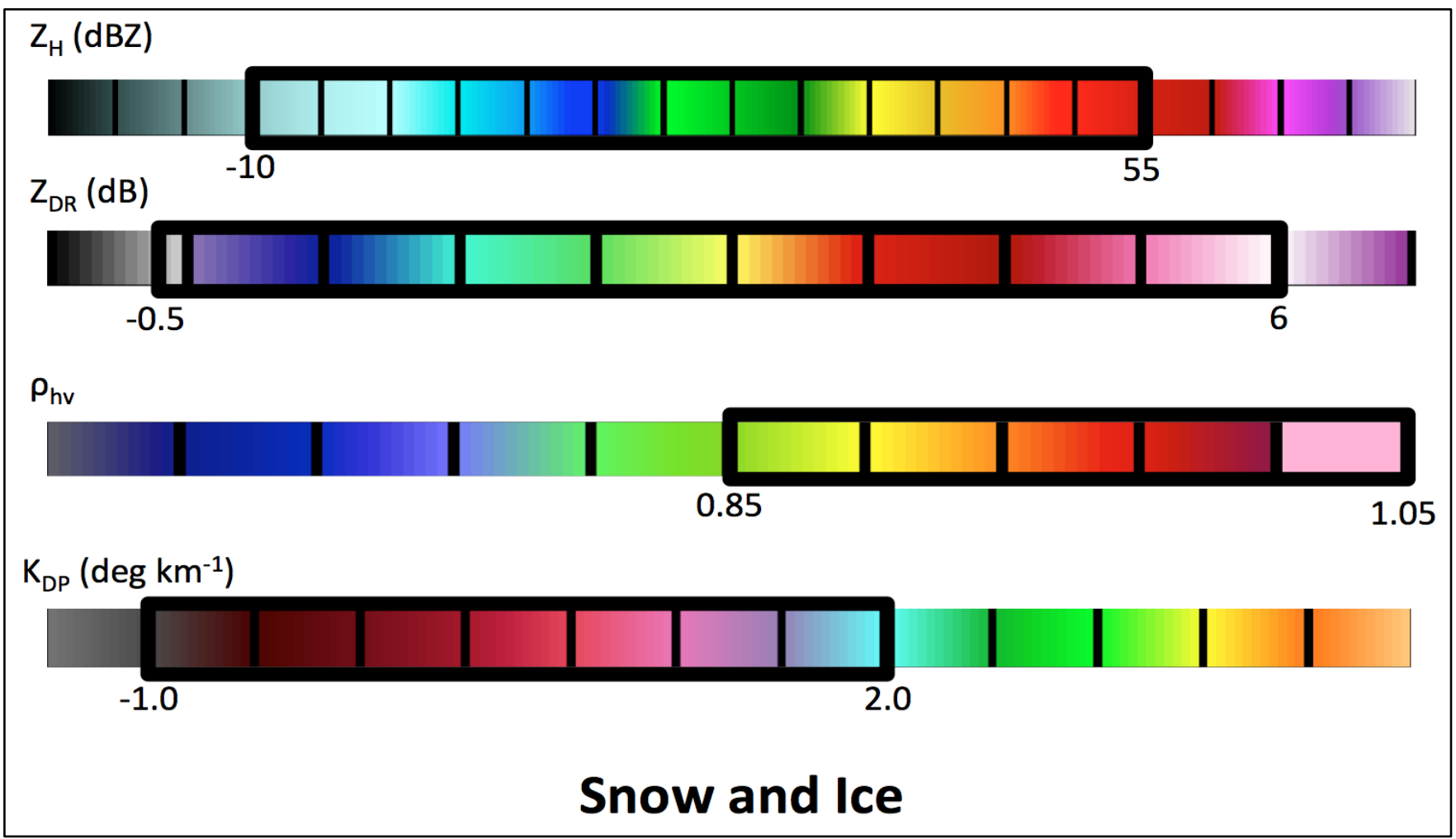

Figure A3. Approximate ranges of S-band values of each polarimetric variable $\left(Z_{\mathrm{H}}, Z_{\mathrm{DR}}, \rho_{\mathrm{hv}}\right.$ or $C C$, and $\left.K_{\mathrm{DP}}\right)$ for snow and ice crystals. Here, the values include dry and wet snow, and pristine crystals of any habit.

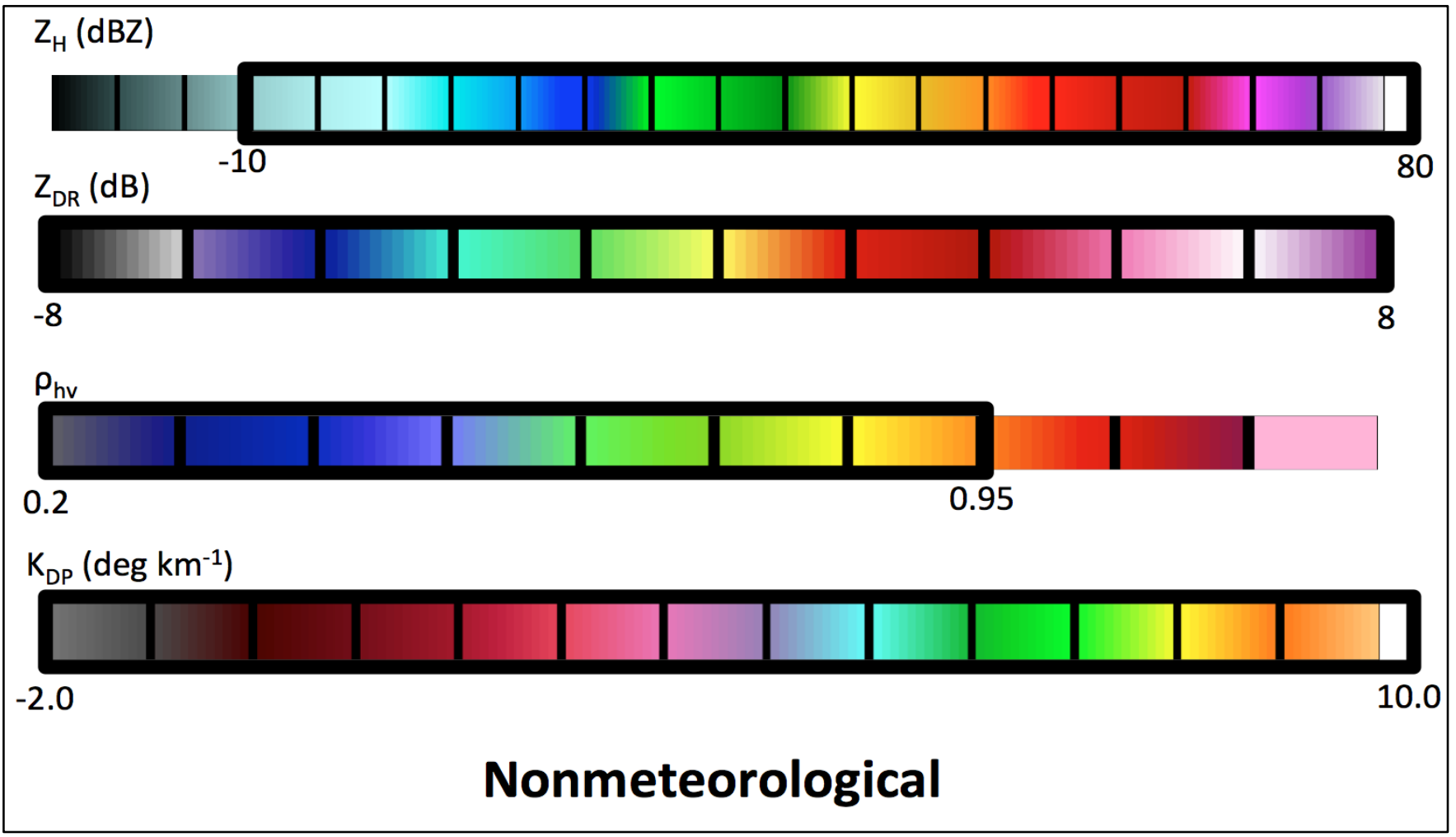

Figure A4. Approximate range of $S$-band values of each polarimetric variable $\left(Z_{H}, Z_{\mathrm{DR}}, \rho_{\mathrm{hv}}\right.$ or $C C$, and $\left.K_{\mathrm{DP}}\right)$ for nonmeteorological echoes. Here, we include all types of nonmeteorological scatterers (e.g., biological, clutter, tornadic debris, etc.). 
proximate ranges that may be observed by $\mathrm{S}$-band polarimetric WSR-88D radars. Additionally, the categories are inclusive of a range of categories for each hydrometeor type (e.g., rain includes all intensities and "big drops"; hail and graupel include all sizes as well as dry and wet particles). For more specific values for the individual categories of the hydrometeor classification algorithm, see the WDTB training "flipchart" (available online from the Warning Decision Training Branch at www.wdtb.noaa.gov/ courses/dualpol/Outreach/DualPol-Flipchart.pdf). The color scales used here are representative of those used in graphical displays, notably the National Climatic Data Center Weather and Climate Toolkit.

\section{REFERENCES}

Andrić, J., M. R. Kumjian, D. S. Zrnić, J. M. Straka, and V. M. Melnikov, 2013: Polarimetric signatures above the melting layer in winter storms: An observational and modeling study. J. Appl. Meteor. Climatol., 52, 682700 .

Aydin, K., and T. A. Seliga, 1984: Radar polarimetric backscattering properties of conical graupel. J. Atmos. Sci., 41, 1887-1892.

, and Y. Zhao, 1990: A computational study of polarimetric radar observables in hail. IEEE Trans. Geosci. Remote Sens., 28, 412-422.

, T. A. Seliga, and V. Balaji, 1986: Remote sensing of hail with a dual linear polarized radar. J. Climate Appl. Meteor., 25, 1475-1484.

Bachmann, S. M., and D. S. Zrnić, 2007: Spectral density of polarimetric variables separating biological scatterers in the VAD display. J. Atmos. Oceanic Technol., 24, 1186-1198.

, and _ 2008: Suppression of clutter residue in weather radar reveals birds' corridors over urban area. IEEE Geosci. Rem. Sens. Lett., 5 (2), 128-132.

Balakrishnan, N., and D. S. Zrnić, 1990a: Estimation of rain and hail rates in mixed-phase precipitation. J. Atmos. Sci., 47, 565-583.

, and __ 1990b: Use of polarization to characterize precipitation and discriminate large hail. J. Atmos. Sci., 47, 1525-1540.

Beard, K. V., and C. Chuang, 1987: A new model for the equilibrium shape of raindrops. J. Atmos. Sci., 44, 1509-1524.

Bechini, R., L. Baldini, and V. Chandrasekar, 2013: Polarimetric radar observations in the ice region of precipitating clouds at $\mathrm{C}$-band and $\mathrm{X}$-band radar frequencies. J. Appl. Meteor. Climatol., 52, 1147-1169.

Bodine, D. J., M. R. Kumjian, R. D. Palmer, P. L. Heinselman, and A. V. Ryzhkov, 2013: Tornado damage estimation using polarimetric radar. Wea. Forecasting, 28, 139-158.
Borowska, L., D. S. Zrnić, A. V. Ryzhkov, P. Zhang, and C. Simmer, 2011: Polarimetric estimates of a 1-month accumulation of light rain with a $3-\mathrm{cm}$ wavelength radar. J. Hydrometeor., 12, 1024-1039.

Brandes, E. A., and K. Ikeda, 2004: Freezing-level estimation with polarimetric radar. J. Appl. Meteor., 43, 1541-1553.

, G. Zhang, and J. Vivekanandan, 2002: Experiments in rainfall estimation with a polarimetric radar in a subtropical environment. J. Appl. Meteor., 41, 674-685.

Bringi, V. N., and V. Chandrasekar, 2001: Polarimetric Doppler Weather Radar: Principles and Applications. Cambridge University Press, 636 pp.

, J. Vivekanandan, and J. D. Tuttle, 1986: Multiparameter radar measurements in Colorado convective storms. Part II: Hail detection studies. J. Atmos. Sci., 43, 2564-2577.

, M. Thurai, K. Nakagawa, G. Huang, T. Kobayashi, A. Adachi, H. Hanado, and S. Sekizawa, 2006: Rainfall estimation from C-band polarimetric radar in Okinawa, Japan: Comparison with 2D-video disdrometer and 400 $\mathrm{MHz}$ wind profiler. J. Meteor. Soc. Japan, 84, 705724.

Browne, I. C., and N. P. Robinson, 1952: Cross-polarization of the radar melting band. Nature, 170, 1078-1079.

Caylor, I. J., and V. Chandrasekar, 1996: Time-varying ice crystal orientation in thunderstorms observed with multiparameter radar. IEEE Trans. Geosci. Remote Sens., 34, 847-858.

Dennis, A. S., and D. J. Musil, 1973: Calculations of hailstone growth and trajectories in a simple cloud model. J. Atmos. Sci., 30, 278-288.

Doviak, R. J., and D. S. Zrnić, 1993: Doppler Radar and Weather Observations. Dover Publications, 562 pp.

Gershenzon, Yu. M., and A. B. Shupyatsky, 1961: Scattering of elliptically polarized radio waves by nonspherical atmospheric particles. Tr. Cent. Aerolog. Obs., 36, 102-108 (in Russian).

Giangrande, S. E., and A. V. Ryzhkov, 2008: Estimation of rainfall based on the results of polarimetric echo classification. J. Appl. Meteor. Climatol., 47, 24452462.

, and J. M. Krause, 2005: Automatic detection of the melting layer with a polarimetric prototype of the WSR-88D radar. Preprints, 32nd Int. Conf. on Radar Meteorology, Albuquerque, NM, Amer. Meteor. Soc., 11R.2. [Available online at ams.confex.com/ams/ pdfpapers/95894.pdf.]

, J. M. Krause, and A. V. Ryzhkov, 2008: Automatic designation of the melting layer with a polarimetric prototype of the WSR-88D radar. J. Appl. Meteor. Climatol., 47, 1354-1364.

Gosset, M., 2004: Effect of nonuniform beam filling on the propagation of radar signals at X-band frequencies. Part II: Examination of differential phase shift. J. Atmos. Oceanic Technol., 21, 358-367. 
Heinselman, P. L., and A. V. Ryzhkov, 2006: Validation of polarimetric hail detection. Wea. Forecasting, 21, 839850.

Hendry, A., and G. C. McCormick, 1974: Polarization properties of precipitation particles related to storm structure. J. Rech. Atmos., 8, 189-200.

Herzegh, P. H., and A. R. Jameson, 1992: Observing precipitation through dual-polarization radar measurements. Bull. Amer. Meteor. Soc., 73, 13651374.

Hogan, R. J., P. R. Field, A. J. Illingworth, R. J. Cotton, and T. W. Choularton, 2002: Properties of embedded convection in warm-frontal mixed-phase cloud from aircraft and polarimetric radar. Quart. J. Roy. Meteor. Soc., 128, 451-476.

Holroyd E. W., III, 1964: A suggested origin of conical graupel. J. Appl. Meteor., 3, 633-636.

Hubbert, J., and V. N. Bringi, 1995: An iterative filtering technique for the analysis of copolar differential phase and dual-frequency radar measurements. J. Atmos. Oceanic Technol., 12, 643-648.

, L. D. Carey, and S. Bolen, 1998: CSU-CHILL polarimetric radar measurements from a severe hail storm in eastern Colorado. J. Appl. Meteor., 37, 749775 .

, S. M. Ellis, M. Dixon, and G. Meymaris, 2010a: Modeling, error analysis, and evaluation of dualpolarization variables obtained from simultaneous horizontal and vertical polarization transmit radar. Part I: Modeling and antenna errors. J. Atmos. Oceanic Technol., 27, 1583-1598. , and _ 2010b: Modeling, error analysis, and evaluation of dual-polarization variables obtained from simultaneous horizontal and vertical polarization transmit radar. Part II: Experimental data. J. Atmos. Oceanic Technol., 27, 1599-1607.

Hunter, I. M., 1954: Polarization of radar echoes from meteorological precipitation. Nature, 173, 165-166.

Ivić, I. R., D. S. Zrnić, and T.-Y. Yu, 2009: The use of coherency to improve signal detection in dualpolarization weather radars. J. Atmos. Oceanic Technol., 26, 2474-2487.

Jameson, A. R., 1983a: Microphysical interpretation of multi-parameter radar measurements in rain. Part I: Interpretation of polarization measurements and estimation of raindrop shapes. J. Atmos. Sci., 40, 17921802.

1983b: Microphysical interpretation of multiparameter radar measurements in rain. Part II: Estimation of raindrop distribution parameters by combined dual-wavelength and polarization measurements. J. Atmos. Sci., 40, 1803-1814.

1985a: Microphysical interpretation of multiparameter radar measurements in rain. Part III: Interpretation and measurement of propagation differential phase shift between orthogonal linear polarizations. J. Atmos. Sci., 42, 607-614.

1985b: Deducing the microphysical character of precipitation from multiple-parameter radar polarization measurements. J. Climate Appl. Meteor., 24, 10371047.

, and E.A. Mueller, 1985: Estimation of propagationdifferential phase shift from sequential orthogonal linear polarization radar measurements. J. Atmos. Oceanic Technol., 2, 133-137.

Jones, T. A., S. A. Christopher, and W. Petersen, 2009: Dual-polarization radar characteristics of an apartment fire. J. Atmos. Oceanic Technol., 26, 2257-2269.

Kennedy, P. C, and S. A. Rutledge, 2011: S-band dualpolarization radar observations of winter storms. $J$. Appl. Meteor. Climatol., 50, 844-858.

Knight, C. A., and N. C. Knight, 1973: Conical graupel. J. Atmos. Sci., 30, 118-124.

Kumjian, M. R., 2013a: Principles and applications of dualpolarization weather radar. Part II: Warm- and coldseason applications. J. Operational Meteor., 1 (20), 243-264.

, 2013b: Principles and applications of dualpolarization weather radar. Part III: Artifacts. J. Operational Meteor., 1 (21), 265-274.

, and A. V. Ryzhkov, 2008: Polarimetric signatures in supercell thunderstorms. J. Appl. Meteor. Climatol., 47, 1940-1961.

, and __, 2009: Storm-relative helicity revealed from polarimetric radar measurements. J. Atmos. Sci., 66, $667-685$.

, and __, 2012: The impact of size sorting on the polarimetric radar variables. J. Atmos. Sci., 69, 20422060.

, J. C. Picca, S. M. Ganson, A. V. Ryzhkov, J. Krause, D. Zrnić, and A. Khain, 2010a: Polarimetric radar characteristics of large hail. Preprints, 25th Conf. on Severe Local Storms, Denver, CO, Amer. Meteor. Soc., 11.2. [Available online at ams.confex.com/ams/pdf papers/176043.pdf.]

, A. V. Ryzhkov, V. M. Melnikov, and T. J. Schuur, 2010b: Rapid-scan super-resolution observations of a cyclic supercell with a dual-polarization WSR-88D. Mon. Wea Rev., 138, 3762-3786.

Long, M. W., 2001: Radar Reflectivity of the Land and Sea. 3rd ed. Artech House, Inc., 534 pp.

Magono, C., and C. W. Lee, 1966: Meteorological classification of natural snow crystals. J. Fac. Sci., Hokkadio Univ., Ser. VII, 2, 321-335.

Maki, M., S. G. Park, and V. N. Bringi, 2005: Effect of natural variations in raindrop size distributions on rain rate estimators of $3 \mathrm{~cm}$ wavelength polarimetric radar. J. Meteor. Soc. Japan, 83, 871-893.

McCormick, G. C., and A. Hendry, 1972: The study of precipitation backscatter at $1.8 \mathrm{~cm}$ with a polarization diversity radar. Preprints, 15th Conf. on Radar Meteorology, Champaign-Urbana, IL, Amer. Meteor. 
Soc., 35-38.

, and __ 1975: Principles for the radar determination of the polarization properties of precipitation. Rad. Sci., 10, 421-434.

Melnikov, V. M., D. S. Zrnić, R. M. Rabin, and P. Zhang, 2008: Radar polarimetric signatures of fire plumes in Oklahoma. Geophys. Res. Lett., 35, L14815. , and _ 2009: Polarimetric radar properties of smoke plumes: A model. J. Geophys. Res., 114, D21204.

Minervin, V. E., and A. B. Shupyatsky, 1963: Radar method of determining the phase state of clouds and precipitation. Tr. Cent. Aerolog. Obs., 47, 63-84 (in Russian).

Morgunov, S. P., and A. B. Shupyatsky, 1964: Evaluation of artificial modification efficiency from the polarization characteristics of the echo signal. Tr. Cent. Aerolog. Obs., 57, 49-54 (in Russian).

Nelson, S. P., 1983: The influence of storm flow structure on hail growth. J. Atmos. Sci., 40, 1965-1983.

Newell, R. E., S. G. Geotis, M. L. Stone, and A. Fleisher, 1955: How round are raindrops? Proc., Fifth Weather Radar Conf., Boston, MA, Amer. Meteor. Soc., 261268.

Picca, J. C., and A. V. Ryzhkov, 2012: A dual-wavelength polarimetric analysis of the 16 May 2010 Oklahoma City extreme hailstorm. Mon. Wea. Rev., 140, 13851403.

Pruppacher, H. R., and K. V. Beard, 1970: A wind tunnel investigation of the internal circulation and shape of water drops falling at terminal velocity in air. Quart. J. Roy. Meteor. Soc., 96, 247-256.

, and R. L. Pitter, 1971: A semi-empirical determination of the shape of cloud and raindrops. $J$. Atmos. Sci., 28, 86-94.

Rasmussen, R. M., and A. J. Heymsfield, 1987: Melting and shedding of graupel and hail. Part I: Model physics. J. Atmos. Sci., 44, 2754-2763.

, V. Levizzani, and H. R. Pruppacher, 1984: A wind tunnel and theoretical study on the melting behavior of atmospheric ice particles: III. Experiment and theory for spherical ice particles of raidus $>500 \mu \mathrm{m}$. J. Atmos. Sci., 41, 381-388.

Rinehart, R. E., 2004: Radar for Meteorologists. Rinehart, $482 \mathrm{pp}$.

Ryzhkov, A. V., 2007: The impact of beam broadening on the quality of radar polarimetric data. J. Atmos. Oceanic Technol., 24, 729-744.

D. S. Zrnić, 1998: Beamwidth effects on the differential phase measurements of rain. J. Atmos. Oceanic Technol., 15, 624-634.

_, and __, 2007: Depolarization in ice crystals and its effect on radar polarimetric measurements. J. Atmos. Oceanic Technol., 24, 1256-1267.

P. Zhang, R. Doviak, and C. Kessinger, 2002: Discrimination between weather and sea clutter using
Doppler and dual-polarization weather radars. XXVII General Assembly of the International Union of Radio Science, Maastricht, Netherlands, International Union of Radio Science, CD-ROM, 1383.

, T. J. Schuur, D. W. Burgess, P. L. Heinselman, S. E. Giangrande, and D. S. Zrnić, 2005a: The Joint Polarization Experiment: Polarimetric rainfall measurements and hydrometeor classification. Bull. Amer. Meteor. Soc., 86, 809-824. , __ _ _ and D. S. Zrnić, 2005b: Polarimetric tornado detection. J. Appl. Meteor., 44, 557-570.

, S. E. Giangrande, and T. J. Schuur, 2005c: Rainfall estimation with a polarimetric prototype of WSR-88D. J. Appl. Meteor., 44, 502-515.

P. Zhang, and J. Krause, 2011: Simultaneous measurements of heavy rain using S-band and C-band polarimetric radars. Preprints, 35th Conf. on Radar Meteor., Pittsburgh, PA, Amer. Meteor. Soc., 17.1. [Available online at ams.confex.com/ams/35Radar/web program/Manuscript/Paper191242/QPE\%20paper.pdf.]

Sachidananda, M., and D. S. Zrnić, 1985: ZDR measurement considerations for a fast scan capability radar. Rad. Sci., 20, 907-922.

, and __, 1986: Differential propagation phase shift and rainfall rate estimation. Radio Sci., 21, 235-247.

, and __, 1987: Rain rate estimates from differential polarization measurements. J. Atmos. Oceanic Technol., 4, 588-598.

Schneebeli, M., N. Dawes, M. Lehning, and A. Berne, 2013: High-resolution vertical profiles of X-band polarimetric radar observables during snowfall in the Swiss Alps. $J$. Appl. Meteor., 52, 378-394.

Schönhuber, M., H. E. Urban, P. P. V. Poiares Baptista, W. L. Randeu, and W. Riedler, 1997: Weather radar versus 2D-video-disdrometer data. Weather Radar Technology for Water Resources Management, B. Bragg Jr. and O. Massambani, Eds., UNESCO Press, 159-171.

Schuur, T. J., A. V. Ryzhkov, D. S. Zrnić, and M. Schönhuber, 2001: Drop size distributions measured by a 2D video disdrometer: Comparison with dualpolarization radar data. J. Appl. Meteor., 40, 10191034.

, D. E. Forsyth, P. Zhang, and H. D. Reeves, 2012: Precipitation observations with NSSL's X-band polarimetric radar during the SNOW-V10 campaign. Pure and Appl. Geophys., doi:10.1007/s00024-0120569-2.

Seliga, T. A., and V. N. Bringi, 1976: Potential use of radar differential reflectivity measurements at orthogonal polarizations for measuring precipitation. J. Appl. Meteor., 15, 69-76.

, and _, 1978: Differential reflectivity and differential phase shift: Applications in radar meteorology. Radio Sci., 13, 271-275.

, R. G. Humphries, and J. I. Metcalf, 1990: Polarization diversity in radar meteorology: Early developments. 
Radar in Meteorology: Battan Memorial and 40th Anniversary Radar Meteorology Conference, D. Atlas, Ed., Amer. Meteor. Soc., 109-114.

Shupyatsky, A. B., 1959: Radar scattering by nonspherical particles. Trans. Cent. Aerolog. Obs., 30, 39-52 (in Russian).

, and S. P. Morgunov, 1963: The application of polarization methods to radar studies of clouds and precipitation. Tr. Vsesoiuznoe Nauchi Meteor. Soveshchaniia Leningrad, 295-305 (in Russian).

Straka, J., D. S. Zrnić, and A. V. Ryzhkov, 2000: Bulk hydrometeor classification and quantification using polarimetric radar data: Synthesis of relations. J. Appl. Meteor., 39, 1341-1372.

Thurai, M., and V. N. Bringi, 2005: Drop axis ratios from a 2D video disdrometer. J. Atmos. Oceanic Technol., 22, 966-978.

Tokay, A., P. G. Bashor, E. Habib, T. Kasparis, 2008: Raindrop size distribution measurements in tropical cyclones. Mon. Wea. Rev., 136, 1669-1685.

Trömel, S., M. R. Kumjian, A. V. Ryzhkov, C. Simmer, and M. Diederich, 2013: Backscatter differential phaseEstimation and variability. J. Appl. Meteor. Climatol., 52, 2529-2548.

Wakimoto, R. M., and V. N. Bringi, 1988: Dualpolarization observations of microbursts associated with intense convection: The 20 July storm during the MIST project. Mon. Wea. Rev., 116, 1521-1539.

Wexler, R., 1955: An evaluation of the physical effects in the melting layer. Proc., Fifth Weather Radar Conf., Boston, MA, Amer. Meteor. Soc., 329-334.

Zrnić, D. S., and A. V. Ryzhkov, 1998: Observations of insects and birds with polarimetric radar. IEEE Trans. Geosci. Remote Sens., 36, 661-668. , and __ 1999: Polarimetry for weather surveillance radars. Bull. Amer. Meteor. Soc., 80, 389-406. , and _ 2004: Polarimetric properties of chaff. $J$. Atmos. Oceanic Technol., 21, 1017-1024. , N. Balakrishnan, C. L. Ziegler, V. N. Bringi, K. Aydin, and T. Matejka, 1993: Polarimetric signatures in the stratiform region of a mesoscale convective system. J. Appl. Meteor., 32, 678-693.

, V. M. Melnikov, and J. K. Carter, 2006a: Calibrating differential reflectivity on the WSR-88D. J. Atmos. Oceanic Technol., 23, 944-951. and A. V. Ryzhkov, 2006b: Correlation coefficients between horizontally and vertically polarized returns from ground clutter. J. Atmos. Oceanic Technol., 23, 381-394. 